\title{
Encountering Resistance: Qualitative Insights from the Quantitative Sampling of Ex-Combatants in Timor-Leste
}

Kate Roll, University of Oxford

ABSTRACT This article highlights the contribution of randomized, quantitative sampling techniques to answering qualitative questions posed by the study. In short it asks: what qualitative insights do we derive from quantitative sampling processes? Rather than simply being a means to an end, I argue the sampling process itself generated data. More specifically, seeking out more than 220 geographically dispersed individuals, selected though a randomized cluster sample, resulted in the identification of relationship patterns, highlighted extant resistance-era hierarchies and patronage networks, as well as necessitated deeper, critical engagement with the sampling framework. While this discussion is focused on the study of former resistance members in Timor-Leste, these methodological insights are broadly relevant to researchers using mixed methods to study former combatants or other networked social movements.

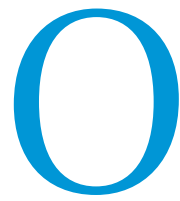

n May 20, 2012, Timor-Leste celebrated 10 years of independence-a milestone in the country's emergence from 24 years of Indonesian occupation. This postconflict period has been one of profound social, economic, and political change, and renegotiating the role of former resistance members in independent Timor-Leste has proved a central challenge. One arena in which this renegotiation has taken place is the government's extensive and growing pensions program for former fighters and clandestine actors-an effort that has registered approximately 250,000 individuals and now consumes approximately $5 \%$ of the national budget. These programs, and their paradoxical expansion in the light of the decreasing threat posed by former resistance members, are the subjects of my research.

This article, however, focuses on mixed methodology and the research process. More specifically, it highlights the contribution of randomized, quantitative sampling techniques to answering qualitative questions posed by the study. It asks: what qualitative insights do we derive from quantitative sampling processes? Rather than simply being a means to an end, I argue the sampling process itself generated data. More specifically, seeking out more than 220 geographically dispersed individuals, selected through a randomized cluster sample, resulted in the identification of relationship patterns and social networks, as well as necessitated deeper, critical engagement with the sampling framework. Furthermore, interviewing low-level

Kate Roll is a DPhil candidate at the University of Oxford. Her work focuses on post-conflict transitions, specifically ex-combatant reintegration programmes, and state-building. She can be reached at kate.roll@gtc.ox.ac.uk. or marginalized respondents required regularly defying the wishes of key leaders-a frequently uncomfortable process that brought resistance-era hierarchies, which otherwise would have been overlooked, into bright relief.

Rather than engaging with the "paradigm wars" over mixedmethodologies (Denzin 2010), this article explores this practical and underrecognized benefit of mixing approaches. In studies such as mine, the researcher's "methodological bilingualism" (Teddlie and Tashakkori 2003, 45) and simultaneous engagement with quantitative and qualitative questions allows for the recognition and utilization of this potentially rich, secondary data stream. Thus, mixing methodologies has the added value of producing new data on those under study, in addition to being useful for triangulation, expansion, or to address gaps (Greene, Caracelli, and Graham 1989; see Table I). Although this discussion is focused on the study of former resistance members in Timor-Leste, these insights are broadly relevant.

\section{"NAVIGATING" THE REGISTRY}

Just as a map is an abstraction that highlights, obscures, or embellishes certain features of physical terrain, I came to see the government's registry of former Timorese combatants as a social map. The registry, listing participants and their roles, describes the boundaries and structures of the resistance during the conflict. Yet it equally highlights, obscures, and embellishes certain features, evincing rules around inclusion and exclusion. Thus, it serves and reflects the needs of those involved in its production, in this case a series of government commissions. Only in navigating by this map, however, did these dynamics become evident. Examining this representation provides information on what matters to key actors and 
underscores the "work" done by the registry as the official record of participation.

The most challenging and time-consuming aspect of this research, indeed, lay in locating the randomly selected subjects in large part because the majority of survey participants ( $77 \%$ ) lived in rural areas. With each site Ilearned how to better "navigate" by the registry, which included each registrant's name, nom de guerre, birthdate, birth village, resistance-era position, resistance-era grade, and benefit level. This
2005, Ch. 328). In such cases, these titles may be best understood as reflecting an elite vision of the resistance during the conflict, one that emphasized its formal aspects rather than describing individuals' activities or connections to other members.

Registrants and registrars have also falsified these titles, both to inflate or invent service records and to transform and legitimate noninstitutionalized roles. I argue these practices are an essential function of the registration process, rather than evidence of its objective failure

\section{Registrants and registrars have also falsified these titles, both to inflate or invent service records and to transform and legitimate noninstitutionalized roles.}

involved recognizing which pieces of information were accurate as well as identifying the cases in which inaccurate data reliably represented other dynamics. In this manner, seeking out individuals became a game: How could the number of contacts needed to locate the subject be reduced? What were the most efficient questions to ask to find him or her? Which social threads most efficiently reconnect these individuals? How could I, in effect, "reverse engineer" the resistance?

\section{The Fiction of Formal Ties and Importance of Families}

One of the key insights generated through this navigational process, and affirmed through other avenues, was the rift between the representation of resistance structures in the registry and the presence-or, more accurately, absence-of the social connections on the ground that evidence contemporaneous participation. My expectation was that individuals identified in the registry as part of specified resistance-era groups would know and connect me to other listed members in the same subdistrict. I anticipated tapping into cellular structures, composed of tightly knit groups or nodes. Reinforcing this view, the registry limns a portrait of coherent organizational structures, suggesting that connections between comrades and commanders would be easily retraced. Yet this approach to locating comrades often proved ineffective and, accordingly, this "map," inaccurate.

In many cases, local leaders and commanders often did not recognize individuals holding both highly specified positions titles such as "Member of Logistics and Information" or "Representative for the Transportation Section," as well as less specific positions such as "Activist." Within putative groups, there was also a lack of mutual recognition: many women were listed as members or representatives of the Timorese Women's Organisation (OMT) yet they did not know other members within the subdistrict. By contrast, certain titles did accurately describe an individual's responsibilities and signaled his or her prominence in postconflict social networks. For example, positions such as "Head of Keixa"-a midlevel unit of the clandestine networks-were generally widely recognized and keixaleaders have been instrumental in registering and organizing their members in the postconflict period.

The presence of such inconsistencies suggests that many formal titles were either adopted post hoc or that the positions themselves were more symbolic than functional during the resistance. Concerning the latter, one former resistance member testified that, "The structure only existed at the level of the FALINTIL command ... We ourselves did not know exactly what the structure was" (CAVR as social policy. Former resistance members who serve as commissioners have used inclusion on the registry to strengthen their patronage networks, benefiting some low-level members and excluding others. Someone who provided food to a cousin in the armed resistance, may be relabeled as serving as a "Member of the Information and Transportation Section." This new title reinforces a nationalist narrative of both widespread participation and a unified, rational resistance. In this manner, these titles also respond to the delegitimization of resistance forces as "terrorists" and "mere bandits" throughout the conflict and immediate postconflict periods (Moore 2001, 10).

In contrast to the difficulty of retracing resistance structures through recorded position titles, the village of birth emerged as the most important factor in locating respondents: of the 224 respondents, $83 \%$ lived within their village of birth and $91 \%$ lived in the same village, although in a separate household, as other family members. This rate is higher than that found by Porto, Parsons, and Alden (63\%; 2007) and Humphreys and Weinstein $(52 \%$; 2004) in their surveys of postconflict resettlement in Angola and Sierra Leone, respectively. The high percentage of individuals residing in their village of birth reflects displacement patterns during the conflict as well as my own reliance on this data as a starting point for locating subjects.

The utility of place of birth, and thus family ties, also underscores tactical decisions specific to the Timorese conflict. As the resistance reassembled itself in the 1980s, family units and clan networks became the building blocks of the clandestine front, which supported and effectively supplanted the rapidly shrinking guerrilla force. Drawing on family ties helped to address issues around trust, secrecy, and organization, and these structures took the place of or preceded formal organizational structures. Participation, at least initially, for many respondents was also highly personalized: numerous respondents described their contributions as providing food, information, or materials directly to male relatives in the hills rather than in terms of organizational involvement.

\section{Proximity to Power}

Another item on the registry that proved informative was benefits levels, ${ }^{1}$ which I came to read as an indicator of individuals' prominence in communities. The registry became a map of proximity to power centers, indicating the highly political and networked nature of the disarmament, demobilizaion, and reintegration (DDR) process.

The correspondence between community status-and thus being "known" and easy to locate-and higher benefits level has multiple 
origins. Some individuals achieved prominence (and higher benefit levels) by distinguishing themselves during the resistance; in other cases, elites within a community during the Portuguese colonial-era became resistance leaders. Others, however, received high benefit levels after the conflict through their connections to elites. Numerous respondents detailed situations in which commissioners-generally drawn from resistance leadership_inflated family members' records or accepted bribes to do so. More commonly, respondents described how their own benefits levels increased after they received recommendations or letters of support from former commanders. In these cases, proximity to power "hubs"-whether through family connections, service, or financial access-produced higher benefit levels.

This inflation also reflects a systematic effort within the registration commissions to recognize significant contributions that fall outside the legal framework. In the case of individuals involved in the November 12 protests and the resultant Santa Cruz massacre, their participation in a historically significant event is recognized through pension benefits-circumventing the statutory criteria. While none of the nine respondents involved in the protests within my sample met the minimum legal requirements for benefits (4-7years of exclusive dedication ${ }^{2}$, all had received benefits designated for 8-14 years of exclusive service. Such findings expose systematic errors in the sampling framework, but, more importantly, the ways that seemingly unambiguous metrics such as "years of service" are refashioned to reflect other values draws attention to broader political dynamics.

\section{CUTTING AGAINST THE GRAIN}

Whereas using the registry to locate individuals shed light on the patronage relationships and the role of the registry in advancing a particular conflict history, further interactions with local resistance leaders concerning access to randomly selected individuals underscored the ongoing role of resistance-era networks in the lives of former combatants and clandestinos. It also highlighted how leaders often continue to control knowledge production, even more than a decade following the cessation of conflict. Butting up against resistance-era hierarchies thus also demonstrated the advantages of having subjects randomly preselected prior to entering a community as a means of address selection and gatekeeper bias-both issues I encountered while conducting semistructured interviews with ex-combatants and policy makers using snowball sampling in 2010 and 2012. deviate from my sampling design. This bind reflects the broader challenge of researching such networks: how to work with leaders to gain access while also avoiding an "echo-chamber" effect?

The problem of accessing former combatants has been approached in several ways, as noted in the review of the literature. In Peake's 2008 study of the FALINTIL ${ }^{3}$ Reinsertion Assistance Programme (FRAP) in Timor-Leste, the author conducted focus group discussions with and surveyed individuals referred by the district administrators; he notes: "those with close temporal and political linkages stood a greater chance of learning of the meeting than others" (2009, 169). While Peake claims that the participants were "generally representative" $(2009,169)$, he does not further explore how working within these networks may have systematically excluded certain participants and perspectives. If I had used a snowball sample (see Bøås and Hatløy 2008; Mashike 2012) or similar methodology to Peake, it is likely that my access to low-level, marginalized, or opposition party-affiliated respondents would have been blocked, however subtly. Scholars who do not employ randomized sampling tools, in part because of concern with losing access to elite informants, run the risk of amplifying and validating the narratives of these elites-the "echo-chamber" effect (Kuus 2013, 118). In this study, randomized sampling methodologies were thus critical for "cutting against the grain" of resistance hierarchies and facilitating access to individuals not directly aligned with key leaders.

The leaders' concerns about with whom I spoke illustrated their ongoing efforts to control resistance narratives. These leaders cautioned that randomly selected individuals had little to tell me, particularly in regards to the history of the conflict. My interest in "fakers," women, youth, and low-level clandestinos in the postconflict period was seen as misguided and even insulting, creating tension. "Why," many higher-level former resistance members asked, "would you be interested in those individuals? They know nothing!" I was often told that my sample was "rubbish." The leaders were interested in the production of certain types of knowledge about the conflict and the postconflict period, and they also valued the experiences of leaders over those at the resistance's grassroots in the telling of these histories-a question of epistemology (see Medina 2011, 10).

The leaders, however, in some regards, were correct: as noted previously, nonresponse was a problem, particularly among the more marginalized individuals. Survey interviews with women and those with little or no education, for example, often proved

\section{Ineeded to both court leaders as "gatekeepers" while also rejecting their clear wishes for me to deviate from my sampling design. This bind reflects the broader challenge of researching such networks: how to work with leaders to gain access while also avoiding an "echo-chamber" effect?}

\section{Gatekeepers, Elites, and Avoiding the "Echo Chamber"}

As a randomly drawn sample reflects the sampling frame-including its weaknesses or inaccuracies-the sample included mostly lower-level former resistance members as well as many registrants who did not meet the registration criteria. However, this list of respondents conflicted with local leaders' conceptions of whom I should interview; to leaders, these men and women were "nobodies." Uncomfortably, I needed to both court leaders as "gatekeepers" while also rejecting their clear wishes for me to slow and frustrating. As Marshall argues, in qualitative research, "researchers recognize that some informants are 'richer' than others and that these people are more likely to provide insight and understanding for the researcher" $(1996,523)$. However, this may reflect a shared habitus (educated, empowered, accustomed to recounting "history"), rather than "insight," and the investment of time in difficult interviews was a means of resisting the impulse to seek out "richer" sources and (again) reproduce and entrench dominant narratives. This initiative paid off, and grievances repeated by many 
low-level fighters, for example the perception that youths were receiving benefits, coalesced to portray the world turned "upside-down," in which the young were honored and old were forgotten.

Finally, my list of names served as an official document propelling my need to contact low-status individuals (ema kiik). I was able to express sympathy with a leader's view that the subject was "not worth speaking to," yet then point to the printed list as a clear directive to seek out the sampled respondents. The printed list thus served as an important prop, reinforcing the seriousness and technocratic basis of my study. Similarly, when meeting with leaders who were upset that their names were not included on my list, I would explain the process of randomization by stating that a "computer" selected the respondents, not I, to depersonalize the decision. Overall, without the list, rejecting leaders' advice concerning whom I should interview would have been more difficult, impolitic, and impolite.

\section{Encountering Resistance}

In seeking selected individuals, I soon recognized that trying to gain access through formal, state-based systems of power was not sufficient. Former resistance leaders-a decade after the end of the conflict-often maintained authority over their regions and followers and continued to cultivate intelligence networks. This provided important "data" regarding power in postconflict TimorLeste. Making contact with these leaders increased access to critical information, such as road conditions, and improved my safety and credibility. have remained active and relevant, even after a decade of independence (see Myrttinen 2013). Such omissions bring to mind Groger, Mayberry, and Straker's (1999) question: what did we not learn from people who did not talk to us?

\section{CONCLUSION}

This article described the unexpected ways in which the implementation of a randomized cluster sample of more than 220 former fighters and clandestinos emerged as means of critically engaging with the sampling framework and confronting ex-combatant social networks in the postconflict period. Through fieldwork, the process of learning how to find selected individuals shed light on research questions concerning the strength, form, and extent of resistance-era networks. These observations were possible through an approach to fieldwork as a " $24 / 7$ " endeavor, with attention to information generated in both when "on duty" (e.g., interviewing) and "off" (e.g., searching for subjects). As I have discussed here, quantitative data proved an intrinsic by-product of the quantitative sampling process.

This particular research design necessarily reflects the research question and resources available in Timor-Leste. However, the broader advantages of using such random sampling techniques in dialogue with qualitative research are relevant across postconflict contexts. This article also highlights some of the reasons why these techniques produce friction and may strain relationships with elite actors-a risk that the researcher must accept. It is actually at the times that create the most discomfort to the researcher that these techniques are

\section{However, the broader advantages of using such random sampling techniques in dialogue with qualitative research are relevant across postconflict contexts. This article also highlights some of the reasons why these techniques produce friction and may strain relationships with elite actors-a risk that the researcher must accept.}

The ongoing robustness and relative autonomy of these networks was amply illustrated by an encounter in Baucau Villa subdistrict. When I was traveling many kilometres from the main town, a man on a motorbike forced me to pull over to the side of the road, stating that a prominent resistance-era leader he represented wanted to know what I was doing and why I had not sought his permission; an act of intimidation. These encounters provided visceral reminders of resistance-era structures' relevance, including the continuation of key functions around information gathering and dissemination as well as leaders' "ownership" of access to their former comrades. Only in the pursuit of randomly selected subjects were these networks visible-an uncomfortable yet potent strategy.

Finally, using state-based registries can have flaws: important networks exist independent to-or even in defiance of-state institutions. One reason I had not contacted the leader was that he had deliberately chosen not to register. Those who have opted out, include individuals involved in Conselho Popular Democrático da República Democrática de Timor-Leste, a resistance-era antistate actor, while others had tense relationships with the ruling Conselho Nacional de Reconstrução do Timor political party and feel alienated from centers of power in Dili. These leaders and their organizations the most valuable. As such, I argue that these mixed methodologies overall benefit the study of evolving or fractured organizations such as resistance or clandestine movements, which can be so important during war-to-peace transitions, as well as the broader study of networks in social movements and patronage politics.

This methodology, and attention to how the sampling process generates data, stands out in a literature on DDR and postconflict transitions that remains largely polarized between qualitative and quantitative approaches. As mixed methods research expands, Sommer Harrits notes, it is time for "research areas that so far have not participated much in discussions on [mixed methods research], for example, political science and comparative politics" $(2011,150)$ to engage more fully. We must explore the consequences of such methodological decisions and approach qualitative and quantitative research processes as highly intermeshed rather then separate.

\footnotetext{
NOTES

1. Benefits correspond with the years of "exclusive dedication," and benefits are broken into five levels: o-3 years (no payments), 4-7 years (single payment), 8-14 years (pension), 15-19 years (pension), and 20-24 years (pension) of service.

2. Exclusive dedication is defined as periods of armed service, incarceration, or mobilization to remote support bases; periods of unarmed and clandestine sup port are not counted for the purpose of calculating service.
} 
3. Armed Forces for the National Liberation of Timor-Leste (Forças Armadas de Liberatação National de Timor-Leste).

\section{R E F E R E N C E S}

Bøås, Morten, and Anne Hatløy. 2008. "'Getting in, Getting Out': Militia Membership and Prospects for Re-Integration in Post-War Liberia." The Journal of Modern African Studies 46 (1): 33-55.

CAVR (Commission for Reception, Truth, and Reconciliation). 2005. Chega! Dili: CAVR. http://www.cavr-timorleste.org/en/chegaReport.htm

Denzin, N. K. 2010. "Moments, Mixed Methods, and Paradigm Dialogs.” Qualitative Inquiry 16 (6): 419-27.

Greene, J. C., V. J. Caracelli, and W. F. Graham. 1989. "Toward a Conceptual Framework for Mixed-Method Evaluation Designs.” Educational Evaluation and Policy Analysis 11 (3) (January 1): 255-74.

Groger, L., P. S. Mayberry, and J. K. Straker. 1999. "What We Didn't Learn Because of Who Would Not Talk to Us." Qualitative Health Research 9 (6) (November 1): 829-35.

Humphreys, Macartan, and Jeremy M. Weinstein. 2004. "What the Fighters Say: A Survey of Ex-Combatants in Sierra Leone June-August 2003, Interim Report July." Columbia University Press, New York.

Kuus, Merje. 2013. "Foreign Policy and Ethnography: A Sceptical Intervention." Geopolitics 18 (1): 115-31
Marshall, M N. 1996. "Sampling for Qualitative Research." Family Practice 13 (6) (December): 522-25.

Mashike, Lephophotho. 2012. "'You Are a Time Bomb ...' Ex-Combatants in PostConflict South Africa." Society in Transition 35 (1): 87-104.

Medina, José. 2011. “Toward a Foucaultian Epistemology of Resistance: CounterMemory, Epistemic Friction, and Guerrilla Pluralism." Foucault Studies 1 (12): 9-35.

Moore, Samuel. 2001. “The Indonesian Military's Last Years in East Timor: An Analysis of Its Secret Documents." Indonesia 72: 9-44.

Myrttinen, Henri. 2013. "Resistance, Symbolism and the Language of Stateness in Timor-Leste." Oceania 83 (3) (November 20): 208-20.

Peake, Gordon. 2009. "What the Veterans Say: Unpacking DDR in Timor-Leste." In, Security and Post-Conflict Reconstruction: Dealing with Fighters in the Aftermath of War. ed. Robert Muggah, 165-89. New York: Routledge.

Porto, J Gomes, Imogen Parsons, and Chris Alden. 2007. "From Soldiers to Citizens: The Social, Economic and Political Reintegration of UNITA Ex-Combatants." ISS Monograph Series, No. 130.

Sommer Harrits, G. 2011. "More Than Method?: A Discussion of Paradigm Differences Within Mixed Methods Research." Journal of Mixed Methods Research 5 (2) (March 28): 150-66.

Teddlie, C., and A. Tashakkori. 2003. 'Major Issues and Controversies in the Use of Mixed Methods in the Social and Behavioral Sciences.' In, Handbook of Mixed-Methods in Social and Behavioral Research. eds. A. Tashakkori and C. Teddlie. 3-50. Thousand Oaks, CA: Sage. 